\title{
On the Role of Menaquinone in the Reduced Nicotinamide Adenine Dinucleotide Oxidative Pathway of Bacillus brevis
}

\author{
By G. H. FYNN \\ Department of Biochemistry, The University of Manchester, Institute of Science \\ and Technology, P.O. Box 88, Manchester, M60 I $Q D$ \\ AND D. V. THOMAS* AND B. SEDDON \\ Department of Biochemistry, The University of Liverpool, \\ P.O. Box I47, Liverpool, L69 $3 B X$ \\ (Accepted for publication 5 November 197I)
}

SUMMARY

\begin{abstract}
Ultraviolet spectroscopy, partition chromatography and mass spectroscopy showed that the only quinone isolated from Bacillus brevis was menaquinone-7. The concentration of quinone present in electron-transport particles was consistent with its participation as an oxido-reduction component. Loss in NADH oxidase activity after ultraviolet irradiation or pentane extraction correlated with the degradation or removal respectively of menaquinone-7 present in the electron transport particles. Attempts to restore NADH oxidase activity either with ultraviolet-treated or pentane-extracted particles using the natural menaquinone were unsuccessful, although lower menaquinone homologues stimulated activity.
\end{abstract}

\section{INTRODUCTION}

Bacillus brevis ATCC10068 contains an active NADH oxidase system (Seddon \& Fynn, 1970; Seddon \& Fynn, 1971). Electron-transport particles from $B$. brevis possess cytochromes $a, b, c$ and $o$ as well as flavoprotein and a menaquinone (Seddon \& Fynn, 1971). The particulatebound NADH oxidase activity of $B$. brevis is mediated by cytochromes $a, b$ and $c$ and flavoprotein but the physiological function of menaquinone or cytochrome $o$ in this system is not known. The present investigation was undertaken in an attempt to elucidate the possible participation of quinone in the particulate-bound NADH oxidase pathway of B. brevis.

\section{METHODS}

Organism, growth and maintenance. Bacillus brevis ATCC 10068 was maintained and grown as described by Seddon \& Fynn (197I). In addition the organism was grown at $30^{\circ}$ under rotary shake conditions, and, when required, the glycerol-asparagine (GA) medium was replaced by a peptone-yeast extract (PYE) medium of the following composition $(\mathrm{g} / \mathrm{l})$ : peptone, IO; yeast extract, $3 ; \mathrm{NaCl}, 5 ; \mathrm{pH} 7 \cdot 0$. Cultures were harvested towards the end of logarithmic growth and washed with O.I M-tris-HCl (pH 7.4) (Seddon \& Fynn, 1970).

Preparation of electron-transport particles (ETP). A suspension of washed organisms was extruded through a cooled French pressure cell and subcellular fractions obtained as described by Seddon \& Fynn (1970). The fraction sedimented at $105,000 \mathrm{~g}$ was used for studies of ETP NADH oxidase activity. In certain experiments, where the distribution of

* Present address: Institute of Psychiatry, de Crespigny Park, Denmark Hill, London, S.E. 5. 
quinone and NADH oxidase activity was assayed, the unfractionated $15,000 \mathrm{~g}$ supernatant fraction ( $15 \mathrm{~S}$ ) and the $105,000 \mathrm{~g}$ supernatant fractions (105S) were used for assay.

Extraction and purification of quinone from whole cells. Six litres of medium were harvested and the organisms (wet pellet) were resuspended in $100 \mathrm{ml}$ of methanol and disrupted with a Polytron macerator at o to $5^{\circ}$ for $15 \mathrm{~s}$ intervals over a period of $2 \mathrm{~min}$. An equal volume of petroleum ether (b.p. 40 to $60^{\circ}$ ) was added and the mixture was shaken. The two layers were separated and the methanol fraction was twice re-extracted with an equal volume of petroleum ether. The petroleum ether fractions were combined, dried over anhydrous $\mathrm{NaSO}_{4}$, filtered and evaporated to approximately $5 \mathrm{ml}$ in a rotary evaporator and then evaporated to dryness under nitrogen. The residue was dissolved in cyclohexane and purified by thin-layer chromatography using rhodamine $6 \mathrm{G}$ impregnated silica-gel plates $(250 \mu \times$ $20 \mathrm{~cm}^{2}$ ) previously washed with ether. The developing solvent was petroleum ether (b.p. 40 to $60^{\circ}$ )-diethyl ether (I9: $\left.\mathrm{I}, \mathrm{v} / \mathrm{v}\right)$. Quinones were extracted from the plates with freshly distilled ether.

Extraction of quinone from ETP. Lyophilized ETP were mechanically homogenized with pentane (Szarkowska, I966). Where the distribution of quinone was investigated the ${ }^{5} \mathrm{~S}$ and ${ }_{105} \mathrm{~S}$ fractions were assayed. Pentane fractions were evaporated to dryness under nitrogen or with a rotary evaporator.

Identification of quinone. U.v. absorption spectra of all lipid extracts were made as described by Seddon \& Fynn (I97I) except that cyclohexane replaced ethanol as solvent. Reversed-phase thin-layer chromatography was used to identify the quinone (Randerath, I966; Seddon \& Fynn, I97I) with acetone: $\mathrm{H}_{2} \mathrm{O}(97: 3, \mathrm{v} / \mathrm{v})$ as developing solvent. Standard menaquinones $(-5,-7,-9$ and -10$)$ were used for comparison. Mass spectroscopy was carried out on a purified quinone sample using an AEI-I 2 mass spectrometer (source temperature $\left.200^{\circ}\right)$.

Quantitative estimation of quinone. The concentration of quinone was determined from the extinction at $249 \mathrm{~nm}$ using a molecular absorbance coefficient of 19,000 (Isler \& Wiss, 1959).

Quantitative estimation of cytochromes. All cytochromes were estimated as described by Seddon \& Fynn (I97I) except that the content of cytochrome $o$ was determined using $\epsilon=170,000$ (4I5 $-432 \mathrm{~nm}$, i.e. peak minus trough according to Daniel, 1970).

$N A D H$ oxidase activity. This was measured either spectrophotometrically or polarographically (Seddon \& Fynn, 1970).

Irradiated particles. Slowly stirred volumes ( 3 to $4 \mathrm{ml}$ ) of ETP (40 to $50 \mathrm{mg}$ protein) were irradiated at $366 \mathrm{~nm}$ using a model $\mathrm{M}$ u.v. lamp (Englhard-Hanovia, Slough, Buckinghamshire) at 0 to $5^{\circ}$ similar to the procedure of Brodie \& Ballantine (1960). U.v. absorption spectra of pentane extracts in cyclohexane of both irradiated and non-irradiated particles were performed as described by Szarkowska, (I966).

Restoration studies. ETP (40 to $50 \mathrm{mg}$ protein) extracted with pentane (Szarkowska, 1966) as well as ETP extracted by the method of Ernster, Lee, Norling \& Persson (1969) were used in these studies. U.v.-irradiated particles, obtained as described above, were also used in attempts to restore NADH oxidase activity. Restoration of activity was attempted in three ways: (i) ethanol solutions ( $0.05 \mathrm{ml}$ or less) containing quinone (I0 to 150 nmoles) were added to the ETP both before and after the commencement of oxidase activity with NADH (controls were conducted with ethanol alone); (ii) pentane-extracted particles were washed with a tenfold excess of quinone (Ernster et al. 1969); (iii) suspensions of quinones (formed by dissolving the quinone in a minimum amount of ethanol followed by the addition of distilled water to a final concentration of $3 \mathrm{mM}$ and sonication for three $\mathrm{IO}$ s intervals at 


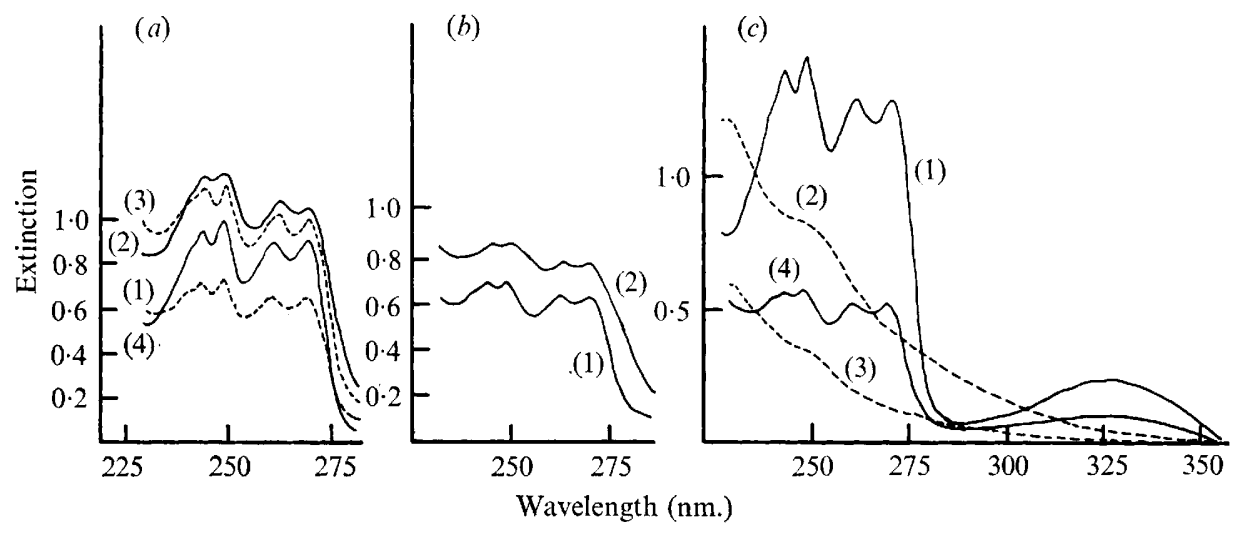

Fig. I. (a) Spectra of lipid extracts from whole cells of Bacillus brevis. All spectra are of petroleum ether $\left(40\right.$ to $\left.60^{\circ}\right)$ extracts in cyclohexane. Trace (4) was obtained after purification using rhodamine $6 \mathrm{G}$ impregnated silica-gel plates with petroleum ether $\left(40\right.$ to $\left.60^{\circ}\right)$ - diethyl ether $(19: \mathrm{I}, \mathrm{v} / \mathrm{v})$ as developing solvent. (I) Organisms grown on GA medium at $30^{\circ} ;(2)$ organisms grown on GA medium at $37^{\circ} ;(3)$ and (4) organisms grown on PYE medium at $30^{\circ}$.

(b) Spectra of pentane extracts of Bacillus brevis ETP. Both spectra are for pentane extracts (Szarkowska ,1966) in cyclohexane. (I) ETP from organisms grown on PYE medium at $30^{\circ}$; (2) ETP from organisms grown on GA medium at $37^{\circ}$.

(c) Effect of u.v. irradiation on the spectral characteristics of MK-7 and the endogeneous quinone of Bacillus brevis ETP. ETP protein $(42 \mathrm{mg})$, obtained from organisms grown on PYE medium at $30^{\circ}$, was divided equally into two $3.0 \mathrm{ml}$ volumes of $\mathrm{O}^{\circ} \mathrm{I} \mathrm{M}$-tris- $\mathrm{HCl}$ buffer $(\mathrm{pH} 7 \cdot 4)$. The sample preparation was covered with a silica disc whereas the control was protected from u.v. irradiation using an aluminium-foil cover. Control and sample preparations of authentic MK-7 (3.0 ml of $60 \mu \mathrm{M}$ solutions in ethanol) were treated similarly. U.v. irradiation at $366 \mathrm{~nm}$ and o to $5^{\circ}$ was for a period of $60 \mathrm{~min}$. Irradiated and non-irradiated ETP were extracted with pentane (Szarkowska, 1966) and the spectra made in cyclohexane on a suitably diluted sample. The ethanolic solutions of MK-7 were taken to dryness under nitrogen and spectra made of irradiated and non-irradiated MK-7 samples suitably diluted in cyclohexane. (I), (2) authentic MK-7, non-irradiated and irradiated respectively; (3), (4) quinone extract from irradiated and non-irradiated particles respectively.

o to $5^{\circ}$ whereupon colloidal suspensions formed), $0.05 \mathrm{ml}$ and less, were added to the $\mathrm{NADH}$ oxidase assay medium as described in (i).

Protein determination. Protein was assayed by the method of Lowry, Rosebrough, Farr \& Randall (I95I) using crystalline bovine serum albumin (fraction V) as standard.

Solvents. All solvents were distilled before use; ether was redistilled from reduced iron within $24 \mathrm{~h}$ of use. Diethyl ether and petroleum ether $\left(40\right.$ to $\left.60^{\circ}\right)$ were dried over $\mathrm{Na}-\mathrm{Pb}$. alloy before distillation.

Chemicals and nutrients. Neutralized peptone and yeast extract were obtained from Oxoid Ltd., London. NADH (grade III) was purchased from Sigma Chemical Co., St Louis, Missouri, U.S.A. Bovine serum albumin was obtained from the Armour Pharmaceutical Co. Ltd, Eastbourne, Sussex, and $n$-pentane from British Drug Houses Ltd, Poole, Dorset. Standard menaquinones were a gift from Dr O. Isler of Hoffmann-La Roche, Basle, Switzerland. 


\section{RESULTS}

Quinone of whole cells and subcellular fractions of Bacillus brevis. U.v. absorption spectra (Fig. $1 a, b$ ) and $R_{F}$ values (extracted quinone, 0.43 ; authentic menaquinone-7, 0.45 ) of the quinone extracted from whole cells and ETP of $B$. brevis grown either on GA or PYE media strongly suggested that the quinone was menquinone-7 (MK-7) (Seddon \& Fynn, I97I). Reduction of the oxidized quinone in ethanol using $\mathrm{NaBH}_{4}$ resulted in changes in the absorption spectra characteristic of menquinone reduction as described by (Kröger \& Dadák (I969). Mass spectroscopy data showed a molecular ion at 648 and a base peak at 225 consistent with the structure of MK-7; peaks at 579, 5I I, 443, 375, 307 and 239 showed sequential loss of isoprene units.

$M K-7$ and NADH oxidase activity. Distribution studies showed that NADH oxidase activity, cytochromes and MK-7 are concentrated into the ETP. With cells grown on PYE media the ETP contained $85 \%$ and $90 \%$ of the total NADH oxidase and MK- 7 respectively of the unfractionated ${ }_{5} \mathrm{~S}$ fraction; similarly ETP from cells grown on GA medium contained $76 \%$ and $91 \%$ of the total NADH oxidase and MK-7 respectively. The concentration of MK-7 (4.5 and $3 \cdot x \mu$ moles/g protein for ETP from organisms grown on PYE and GA medium) is in tenfold excess over the cytochromes.

U.v. irradiation of ETP led to the loss of about $80 \%$ of the NADH oxidase activity on prolonged irradiation $(60 \mathrm{~min})$. Such treatment resulted also in the degradation of endogenous MK-7. Authentic MK-7 irradiated in the same manner showed similar changes in spectral characteristics (Fig. I $c$ ).

About $90 \%$ of the endogenous menaquinone is removed by three successive extractions according to the method of Szarkowska (1966). Such treatment led also to losses in NADH oxidase of 80 to $90 \%$ of the original activity. Similar results were obtained using the extraction procedure of Ernster et al. (I969).

All attempts to restore NADH oxidase activity with MK-7 (the endogenous quinone) failed. The lower menaquinone homologues (MK-2 and MK-3) stimulated NADH oxidase activity of a u.v.-irradiated preparation. NADH oxidase activities of $\mathrm{I} 20,20,2 \mathrm{IO}$ and I 20 nmoles $\mathrm{NADH}$ oxidized $/ \mathrm{min} / \mathrm{mg}$ protein were obtained for non-irradiated, irradiated (60 $\mathrm{min}$ ), irradiated + MK-2, and irradiated + MK-3 ETP respectively. Similar results were also obtained with pentane-extracted particles, showing that the lower, water-soluble menaquinones stimulated activity.

\section{DISCUSSION}

These results confirm the presence of menaquinone (MK-7) in Bacillus brevis. That MK-7 is present in both whole cells and ETP of B. brevis and that ubiquinone is absent may be due to menaquinone functioning in electron transport as the quinone participant. Organisms grown on GA medium produce relatively high levels of tyrothricin compared with cells grown on PYE medium (Seddon, I97I). Under conditions of tyrothricin production it has been shown (Seddon \& Fynn, I97I) that the antibiotic inhibits the NADH oxidase activity of the isolated ETP. Since MK-7 concentration levels are similar under both conditions of growth it would seem that the quinone function is not related to antibiotic production.

The MK-7 content of ETP is consistent with its participation as an intermediary oxidoreduction component in electron transport. As is found with Bacillus megaterium (Kröger \& Dadák, 1969), the concentration of $\mathrm{MK}-7$ in $B$. brevis is in tenfold excess over the cytochromes. U.v. irradiation led to a loss of NADH oxidase activity as in Mycobacterium phlei (Brodie \& Ballantine, 1960) and the spectrum of the pentane extract from u.v.-irradi- 
ated particles indicated that MK-7 was degraded as found by Marquez \& Brodie (1970) for MK-8 in the NADH oxidase pathway of a halophilic bacterium. Pentane extraction procedures which removed MK-7 from the ETP also produced corresponding losses in NADH oxidase activity. This evidence therefore implies that MK-7 plays an intermediary role in electron transport between NADH and oxygen.

The failure of MK-7 to restore NADH oxidation of u.v. irradiated or pentane-extracted particles may be due to failure of the techniques used to restore MK-7 to its original site in the ETP or to damage to the structural orientation of the electron-transport system as a whole. Although u.v. irradiation destroys the endogenous menaquinone in Bacillus brevis ETP the mere presence of a modified quinone in the irradiated particles could prevent re-incorporation and thus proper functioning of exogenously added quinone (Knook \& Planta, 197I). Alternatively u.v. irradiation may destroy some other light-sensitive component, not necessarily a quinone, required for NADH oxidation as shown by Murti \& Brodie (1969) in the succinoxidase pathway of Mycobacterium phlei.

In conclusion, these results implicate, but do not prove, the participation of $\mathrm{MK}-7$ in the NADH oxidase electron-transport system of Bacillus brevis. Work is now in progress to locate the lesion induced by u.v. irradiation and pentane extraction and to effect a more successful method of reincorporating MK-7 to its original physiological site.

We wish to thank Dr J. F. Pennock for advice and guidance concerning the characterization of the menaquinone and Dr O. Isler for his gift of menaquinone homologues.

\section{REFERENCES}

Brodie, A. F. \& Ballantine, J. (1960). Oxidative phosphorylation in fractionated bacterial systems. II. The role of vitamin K. Journal of Biological Chemistry 235, 226-23I.

DANiEL, R. M. (1970). The electron transport system of Acetobacter suboxydans with particular reference to cytochrome $o$. Biochimica et biophysica acta 216, 328-341.

Ernster, L., Lee, I. Y., Norling, B. \& Persson, B. (I969). Studies with ubiquinone-depleted submitochondrial particles. European Journal of Biochemistry 9, 299-3I0.

IsLER, O. \& WISS, O. (I959). Chemistry and biochemistry of the K vitamins. Vitamins and Hormones $\mathbf{1 7}$, 53-90.

KNOOK, D. L. \& Planta, R. J. (I97I). Function of ubiquinone in electron transport from reduced nicotinamide adenine dinucleotide to nitrate and oxygen in Aerobacter aerogenes. Journal of Bacteriology ro5, 483-488.

KRÖGER, A. \& DADÁK, V. (I969). On the role of quinones in bacterial electron transport. The respiratory system of Bacillus megaterium. European Journal of Biochemistry Ir, 328-340.

Lowry, O. H., Rosebrough, N. J., Farr, A. L. \& Randall, R. J. (I95I). Protein measurement with the Folin phenol reagent. Journal of Biological Chemistry r93, 265-275.

Marquez, E. D. \& Brodie, A. F. (1970). Electron transport in halophilic bacteria: Involvement of a menaquinone in the reduced nicotinamide adenine dinucleotide oxidase pathway. Journal of Bacteriology 103, 260-262.

Murti, C. R. K. \& Brodie, A. F. (I969). New light-sensitive cofactor required for oxidation of succinate by Mycobacterium phlei. Science, New York 164, 302-304.

Randerath, K. (I966). Thin-layer Chromatography, 2nd edn, p. 187. New York: Academic Press.

SEDDON, B. (197I). Studies concerning the respiratory metabolism of a tryothricin producing strain of Bacillus brevis. Ph.D. Thesis, University of Manchester, Institute of Science and Technology.

SEddon, B. \& FynN, G. H. (1970). Terminal oxidations in Bacillus brevis ATCC 10068. I. The measurement of the NADH oxidase activity of Bacillus brevis ATCC 10068. Biochimica et biophysica acta 216, 435-438.

Seddon, B. \& FynN, G. H. (I97I). Terminal oxidations in Bacillus brevis. II. The electron transport system of Bacillus brevis. Archiv für Mikrobiologie 77, 252-261.

SzarkowsKa, L. (I966). The restoration of DPNH oxidase activity by coenzyme Q (ubiquinone). Archives of Biochemistry and Biophysics $\mathbf{1} 3,519-525$. 